\title{
Prognostic nomogram for inpatients with asthma exacerbation
}

\author{
Wakae Hasegawa'1, Yasuhiro Yamauchi ${ }^{\text {* }}$, Hideo Yasunaga², Hideyuki Takeshima', Yukiyo Sakamoto ${ }^{1}$, Taisuke Jo ${ }^{1,3}$, \\ Yusuke Sasabuchi ${ }^{3}$, Hiroki Matsui ${ }^{2}$, Kiyohide Fushimi $^{4}$ and Takahide Nagase ${ }^{1}$
}

\begin{abstract}
Background: Asthma exacerbation may require a visit to the emergency room as well as hospitalization and can occasionally be fatal. However, there is limited information about the prognostic factors for asthma exacerbation requiring hospitalization, and no methods are available to predict an inpatient's prognosis. We investigated the clinical features and factors affecting in-hospital mortality of patients with asthma exacerbation and generated a nomogram to predict in-hospital death using a national inpatient database in Japan.
\end{abstract}

Methods: We retrospectively collected data concerning hospitalization of adult patients with asthma exacerbation between July 2010 and March 2013 using the Japanese Diagnosis Procedure Combination database. We recorded patient characteristics and performed Cox proportional hazards regression analysis to assess the factors associated with all-cause in-hospital mortality. Then, we constructed a nomogram to predict in-hospital death.

Results: A total of 19,684 patients with asthma exacerbation were identified; their mean age was 58.8 years (standard deviation, 19.7 years) and median length of hospital stay was 8 days (interquartile range, 5-12 days). Among study patients, 118 died in the hospital (0.6\%). Factors associated with higher in-hospital mortality included older age, male sex, reduced level of consciousness, pneumonia, and heart failure. A nomogram was generated to predict the in-hospital death based on the existence of seven variables at admission. The nomogram allowed us to estimate the probability of in-hospital death, and the calibration plot based on these results was well fitted to predict the in-hospital prognosis.

Conclusion: Our nomogram allows physicians to predict individual risk of in-hospital death in patients with asthma exacerbation.

\section{Background}

Asthma is characterized by recurrent respiratory symptoms such as wheeze, shortness of breath, chest tightness, and cough. The intensity of these symptoms varies over time together with the variable expiratory airflow limitation [1]. The treatment of asthma patients in the primary care or an outpatient setting mostly involves inhalation of corticosteroids [2]. However, since a severe exacerbation is often fatal, patients with asthma exacerbation may need to visit the emergency room followed by hospitalization and mechanical ventilation [3-6].

Although asthma mortality in adults has been decreasing since the mid-1990s [7, 8], asthma is still associated

\footnotetext{
* Correspondence: YAMAUCHIY-INT@h.u-tokyo.ac.jp

'Department of Respiratory Medicine, Graduate School of Medicine, The University of Tokyo, 7-3-1 Hongo, Bunkyo-ku, Tokyo 113-8655, Japan Full list of author information is available at the end of the article
}

with 12 deaths per million individuals in Japan, as per data from 2014 [9]. The findings of several studies have suggested that a short-term mortality is associated with patients' disease and drug history, including frequent use of rescue medication [10-12], less use of corticosteroids inhalation [2, 13], frequent asthma attacks, and hospitalization for asthma and impaired lung function $[14,15]$. Nonetheless, there is limited understanding of the prognostic factors for patients with asthma exacerbation requiring hospitalization.

A nomogram is a graphical representation of a multivariable model that is often used for the prognosis evaluation in oncology $[16,17]$. It enables physicians to generate an individual probability of clinical events, such as mortality, by integrating diverse prognostic and determinant variables [17]. With a nomogram, physicians can estimate a patient's individual risk of a specific event at 
the bedside, which can be useful for clinical decisionmaking.

In this study, we aimed to investigate the relationships between patient characteristics and comorbidities at admission as well as the in-hospital mortality of patients with asthma exacerbation using a national inpatient database in Japan. Further, we generated a nomogram to predict the prognosis in patients with asthma exacerbation who required hospital admission.

\section{Methods}

\section{Diagnosis procedure combination (DPC) database}

We investigated the data abstracted from the DPC database, which is a nationwide inpatient database in Japan. The database contains administrative claims data and discharge abstract data. It mainly includes the main diagnoses, comorbidities at admission, and complications occurring during hospitalization that were diagnosed and recorded by the attending physicians and these are indicated in the database using the International Classification of Disease and Related Health Problems, 10th Revision (ICD-10) codes accompanied with text data in Japanese. The database also contains the following patient details: admission status including age, sex, height, and weight; levels of consciousness based on the Japan Coma Scale [18, 19]; levels of dyspnea based on Hugh-Jones classification [20, 21]; discharge status including in-hospital death; and medication used during hospitalization. Japan Coma Scale is defined as follows: 0, alert; I, dull; II, somnolence; and III, coma [18, 19]. The Hugh-Jones classification, which is similar to the Medical Research Council dyspnea scale and widely used in Japan, is defined as follows: I, patient's breathing is as good as that of others with same age and build during work, walking, and climbing hills or stairs; II, patient is able to walk at pace with healthy people of same age and build on the ground level but is unable to keep up on hills or stairs; III, patient is unable to keep up with healthy people on the ground level but is able to walk about a mile or more at their own speed; IV, patient is unable to walk more than 50 yards on the ground level without taking rest; $\mathrm{V}$, patient is breathless while talking or undressing or unable to leave his/her house because of breathlessness; Unspecified, patient cannot to be classified into the above grades as he/she is bedridden [20, 21].

This study was approved by the Institutional Review Board of The University of Tokyo, which waived the requirement for patient informed consent because of the anonymous nature of the data.

\section{Patient selection and data}

We retrospectively collected the data from patients who were admitted due to asthma exacerbation and discharged between 1 July 2010 and 31 March 2013. We included patients aged $\geq 18$ years who were diagnosed with asthma exacerbation (ICD-10 code, J45 asthma or J46 status asthmaticus as the main diagnosis, or the disease that required hospitalization) at admission and received systemic corticosteroid therapy within 2 days of admission. The exclusion criteria were as follows: patients who were transferred to other hospitals within 2 days of admission; those whose data on conscious level, dyspnea level, or body mass index (BMI) were missing; and patients with malignant diseases (C00-97), diffuse panbronchiolitis or bronchiolitis obliterans (J448), bronchiectasis (J47), tracheal or pulmonary tuberculosis (A15-16), acute ischemic heart diseases (I20-24), acute pulmonary embolism (I26), acute aortic aneurysm or dissection (I71), or acute cerebral apoplexy (160-63) at admission. We also excluded the patients who died within 2 days of admission, as endotracheal intubation within 2 days of admission was adopted as a predictor of in-hospital death.

We identified patient characteristics at admission, including age, sex, BMI, consciousness level based on the Japan Coma Scale [18, 19], dyspnea level based on the Hugh-Jones classification [20, 21], ambulance service use, past intubation, seasonality, and requirement for intubation within 2 days of admission. The term "ambulance service use" refers to the patients who were transported to the hospital by ambulance. The term "past intubation" refers to the patients who were intubated before the index hospitalization. Seasonality included spring (March to May), summer (June to August), fall (September to November), and winter (December to February). The comorbidities that were identified using ICD-10 codes and text data in Japanese include chronic obstructive pulmonary disease (COPD, J44), pneumonia (bacterial pneumonia: J13-15, J170; atypical pneumonia: A481, J157, J160; aspiration pneumonia: J69; pneumocystis pneumonia: B59; and eosinophilic pneumonia: J82), interstitial pneumonia (J841, J848-9), heart failure (I50), chronic cerebrovascular disease (I69), chronic liver disease (K70-77), gastroesophageal reflux disease (GERD, K21), and chronic renal failure (N17-19). Other extracted data were patient outcome, including the length of hospital stay and all-cause in-hospital death.

\section{Statistical analysis}

The chi-squared test was used to compare proportions between groups. When data were sparse (expected value $<5)$, we used Fisher's exact test instead of the chi-squared test to compare proportions between the groups. Cox proportional hazards regression analysis was undertaken to assess the factors associated with all-cause in-hospital mortality. The variables significantly associated with inhospital death in the univariate analysis were used in the Cox proportional hazards regression analysis. We then used the variables identified in Cox proportional hazards 
regression analysis to build a nomogram that predicted in-hospital all-cause mortality. The internal validation was performed via a bootstrap method with 1000 resamples, and the calibration plot was derived to evaluate the relationship between predicted probabilities by the nomogram and observed rates. The threshold for significance was set at $P$-value $<0.05$. Statistical analyses were performed using SPSS version 22.0 (IBM Corp., Armonk, NY, USA), and the nomogram was built by $R$ version 3.1.3 (The R Foundation for Statistical Computing, Vienna, Austria).

\section{Results}

Among 19 million patients recorded during 33 months between July 2010 and March 2013, we identified 29,033 patients who were diagnosed with asthma exacerbation at admission and received systemic corticosteroid therapy within 2 days of admission. Among identified patients, 9349 met our exclusion criteria (Fig. 1). Ultimately, 19,684 patients were included in this study. The mean age of the patients was 58.8 years [standard deviation (SD), 19.7]. Among them, 7520 (38.2\%) were male; the mean BMI was $23.7 \mathrm{~kg} / \mathrm{m}^{2}$ (SD, 4.8). The median length of hospital stay was 8 days [interquartile range (IQR), 5-12 days]. Moreover, 118 patients died in the hospital $(0.6 \%)$. The median length of stay for the patients who died during hospitalization was 15 days (IQR, 6.8-40.3 days).

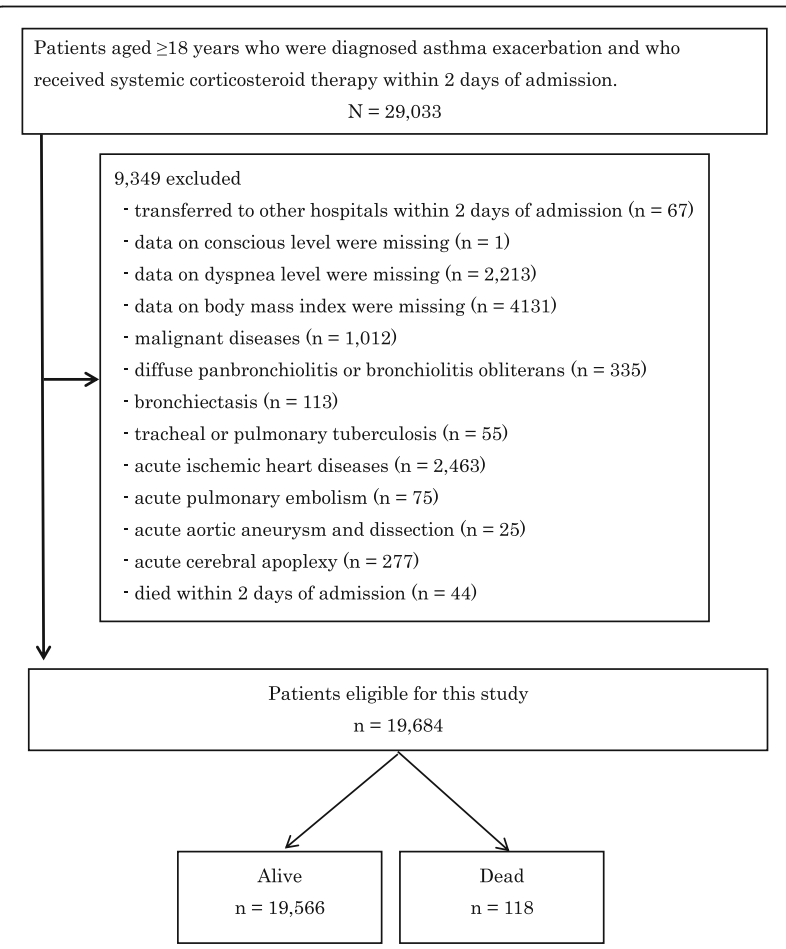

Fig. 1 Flowchart of patient inclusion and exclusion
The data represented in Table 1 show that approximately $30 \%(5361 / 19,684)$ of the patients used ambulance service. In-hospital mortality was significantly related to the following characteristics of patients at the time of admission: older age, male sex, disturbance of consciousness, severe dyspnea, and ambulance service use.

Table 1 Characteristics of inpatients with asthma exacerbation and all-cause in-hospital mortality

\begin{tabular}{|c|c|c|c|}
\hline & Total (\%) & Mortality (\%) & $P$-value \\
\hline \multicolumn{3}{|l|}{ Age (years) } & \multirow[t]{5}{*}{$<0.001$} \\
\hline $18-39$ & $4136(21.0)$ & $1(0.0)$ & \\
\hline $40-69$ & $8440(42.9)$ & $21(0.3)$ & \\
\hline $70-79$ & $3857(19.6)$ & $30(0.8)$ & \\
\hline$\geq 80$ & $3251(16.5)$ & $66(2.0)$ & \\
\hline \multicolumn{3}{|l|}{ Sex } & \multirow[t]{3}{*}{0.038} \\
\hline Male & $7520(38.2)$ & $56(0.7)$ & \\
\hline Female & $12,164(61.8)$ & $62(0.5)$ & \\
\hline \multicolumn{3}{|l|}{$\mathrm{BMI}\left(\mathrm{kg} / \mathrm{m}^{2}\right)$} & \multirow[t]{6}{*}{0.538} \\
\hline$<18.5$ & $2135(10.9)$ & $18(0.8)$ & \\
\hline $18.5-22.9$ & $7743(39.3)$ & $47(0.6)$ & \\
\hline $23.0-24.9$ & $3316(16.9)$ & $19(0.6)$ & \\
\hline $25.0-29.9$ & $4459(22.7)$ & $25(0.6)$ & \\
\hline$>30.0$ & $2031(10.3)$ & $9(0.4)$ & \\
\hline \multicolumn{3}{|c|}{ Consciousness level } & \multirow[t]{5}{*}{$<0.001$} \\
\hline Alert & $18,539(94.2)$ & $83(0.5)$ & \\
\hline Dull & $864(4.4)$ & $18(2.1)$ & \\
\hline Somnolence & $148(0.8)$ & $8(5.4)$ & \\
\hline Coma & $133(0.7)$ & $9(6.8)$ & \\
\hline \multicolumn{3}{|l|}{ Dyspnea grade } & \multirow[t]{6}{*}{$<0.001$} \\
\hline 1 & $3476(17.7)$ & $8(0.2)$ & \\
\hline$\|$ & $3392(17.2)$ & $10(0.3)$ & \\
\hline III & $2971(15.1)$ & $9(0.3)$ & \\
\hline IV & $4797(24.4)$ & $21(0.4)$ & \\
\hline V & $5048(25.6)$ & $70(1.4)$ & \\
\hline \multicolumn{3}{|c|}{ Ambulance service use } & \multirow[t]{3}{*}{0.024} \\
\hline No & $14,323(72.8)$ & $75(0.5)$ & \\
\hline Yes & $5361(27.2)$ & $43(0.8)$ & \\
\hline \multicolumn{3}{|l|}{ Past intubation } & \multirow[t]{3}{*}{0.137} \\
\hline No & $19,576(99.5)$ & $116(0.6)$ & \\
\hline Yes & $108(0.5)$ & $2(1.9)$ & \\
\hline \multicolumn{3}{|c|}{ Season of admission } & \multirow[t]{5}{*}{0.563} \\
\hline Spring & $4225(21.5)$ & $25(0.6)$ & \\
\hline Summer & $4280(21.7)$ & $26(0.6)$ & \\
\hline Autumn & $5476(27.8)$ & $27(0.5)$ & \\
\hline Winter & $5703(29.0)$ & $40(0.7)$ & \\
\hline
\end{tabular}

Abbreviations: BMI Body mass index 
The data represented in Table 2 show that common comorbidities were pneumonia, heart failure, and GERD. In-hospital mortality was related to pneumonia and heart failure.

The number of patients who required mechanical ventilation during hospitalization was 769 (3.9\%). Among them, $85 \%$ patients $(n=649 ; 3.3 \%)$ required mechanical ventilation within 2 days of admission (Table 3 ). The median time from admission to intubation was 0 days (IQR, 0-1 day), and the median length of ventilation period was 2 days (IQR, 1-5 days). Further, $12.1 \%$ of patients who underwent intubation $(n=108 ; 0.5 \%)$ required one or more further episodes of mechanical ventilation during the study period. The data depicted in Table 3 also shows that in-hospital mortality was related to endotracheal intubation within 2 days of admission. However, a total of 24 patients (3.7\%) died after mechanical ventilation.

The data represented in Table 4 shows the Cox proportional hazards regression analysis for all-cause

Table 2 Comorbidities on admission and all-cause in-hospital mortality

\begin{tabular}{|c|c|c|c|}
\hline & Total (\%) & Mortality (\%) & $P$-value \\
\hline \multicolumn{3}{|l|}{ COPD } & 0.054 \\
\hline No & $16,751(85.1)$ & $93(0.6)$ & \\
\hline Yes & $2933(14.9)$ & $25(0.9)$ & \\
\hline \multicolumn{3}{|c|}{ Pneumonia } & $<0.001$ \\
\hline No & $16,960(86.2)$ & $81(0.5)$ & \\
\hline Yes & $2724(13.8)$ & $37(1.4)$ & \\
\hline \multicolumn{3}{|c|}{ Interstitial pneumonia } & 0.344 \\
\hline No & $19,614(99.6)$ & $117(0.6)$ & \\
\hline Yes & $70(0.4)$ & $1(1.4)$ & \\
\hline \multicolumn{3}{|c|}{ Heart failure } & $<0.001$ \\
\hline No & $17,590(89.4)$ & $70(0.4)$ & \\
\hline Yes & $2094(10.6)$ & $48(2.3)$ & \\
\hline \multicolumn{3}{|c|}{ Chronic cerebrovascular disease } & 0.301 \\
\hline No & $19,293(98.0)$ & $114(0.6)$ & \\
\hline Yes & $391(2.0)$ & $4(1.0)$ & \\
\hline \multicolumn{3}{|c|}{ Chronic liver disease } & 0.333 \\
\hline No & $19,486(99.0)$ & $116(0.6)$ & \\
\hline Yes & $198(1.0)$ & $2(1.0)$ & \\
\hline \multicolumn{3}{|l|}{ GERD } & 0.811 \\
\hline No & $18,132(92.1)$ & $108(0.6)$ & \\
\hline Yes & $1552(7.9)$ & $10(0.6)$ & \\
\hline \multicolumn{3}{|c|}{ Chronic renal failure } & 0.387 \\
\hline No & $19,461(98.9)$ & $116(0.6)$ & \\
\hline Yes & $223(1.1)$ & $2(0.9)$ & \\
\hline
\end{tabular}

Abbreviations: COPD Chronic Obstructive Pulmonary Disease, GERD Gastroesophageal reflux diseases
Table 3 Clinical course after admission and all-cause in-hospital mortality

\begin{tabular}{llll}
\hline & Total (\%) & Mortality (\%) & $P$-value \\
\hline Intubation within two days of admission & & $<0.001$ \\
No & $19,035(96.7)$ & $94(0.5)$ & \\
Yes & $649(3.3)$ & $24(3.7)$ & \\
\hline
\end{tabular}

in-hospital mortality. Although ambulance service use was significantly correlated with in-hospital death in the univariate analysis, it was not included in the Cox proportional hazards regression analysis as it is influenced by the patient's background. According to Cox proportional hazards regression analysis, higher mortality among patients with asthma exacerbation was associated with older age, male sex, disturbance of consciousness, pneumonia, and heart failure at admission.

The nomogram was built using the same variables identified in the Cox proportional hazards regression analysis (Fig. 2). It allowed us to estimate the probability of in-hospital death. The concordance index of the nomogram was 0.869 (95\% confidence interval, 0.868-0.869). Internal validation was performed by a bootstrap method with 1000 resamples. The calibration plots are shown in Fig. 3.

\section{Discussion}

We investigated the clinical characteristics, admission status, and all-cause in-hospital mortality of patients with asthma exacerbation who required hospitalization. We also developed a nomogram that predicted in-hospital mortality. Our study revealed that the mortality rate of patients who were admitted due to exacerbation was $0.6 \%$. Moreover, in-hospital mortality was associated with older age, male sex, disturbance of consciousness, pneumonia, and heart failure at admission. A nomogram was generated based on seven variables at admission to predict in-hospital death.

In this study, the in-hospital mortality rate for asthma was $0.6 \%$, which is broadly comparable to the previous reports based on nationally representative data of the US $(0.5 \%)$ [5] and UK (0.43\%) [7]. There may be several reasons behind the difference in asthma-related mortality observed in our study with that observed in previous studies; one of the most likely reasons may be the age difference among patients included in the study. Our study did not include young patients, including infants and children, and the proportion of older patients was higher than that in previous reports. Since young patients with asthma are reported to have relatively favorable outcomes [22-24], it is likely that in-hospital mortality is higher in the present study than previous reports. The proportion of patients who required 
Table 4 Cox proportional hazards regression analysis for all-cause in-hospital mortality

\begin{tabular}{|c|c|c|c|c|}
\hline & & Hazard ratio & $95 \%$ confidence interval & $P$-value \\
\hline \multirow[t]{4}{*}{ Age (years) } & $18-39$ & Reference & & \\
\hline & $40-69$ & 7.46 & $1.00-55.63$ & 0.050 \\
\hline & $70-79$ & 12.13 & $1.64-89.87$ & 0.015 \\
\hline & $\geq 80$ & 21.38 & $2.92-156.46$ & 0.003 \\
\hline Sex (Female) & & 0.61 & $0.42-0.88$ & 0.008 \\
\hline \multirow[t]{4}{*}{ Consciousness level } & Alert & Reference & & \\
\hline & Dull & 1.89 & $1.11-3.21$ & 0.018 \\
\hline & Somnolence & 5.39 & $2.43-11.96$ & $<0.001$ \\
\hline & Coma & 9.68 & $4.18-22.41$ & $<0.001$ \\
\hline \multirow[t]{5}{*}{ Dyspnea grade } & I & Reference & & \\
\hline & $\|$ & 0.79 & $0.31-2.02$ & 0.625 \\
\hline & III & 0.64 & $0.24-1.66$ & 0.354 \\
\hline & IV & 0.67 & $0.29-1.54$ & 0.345 \\
\hline & V & 1.51 & $0.71-3.20$ & 0.284 \\
\hline Intubation within two days of admission & & 1.35 & $0.76-2.40$ & 0.306 \\
\hline Pneumonia & & 1.81 & $1.21-2.69$ & 0.004 \\
\hline Heart failure & & 2.08 & $1.41-3.06$ & $<0.001$ \\
\hline
\end{tabular}

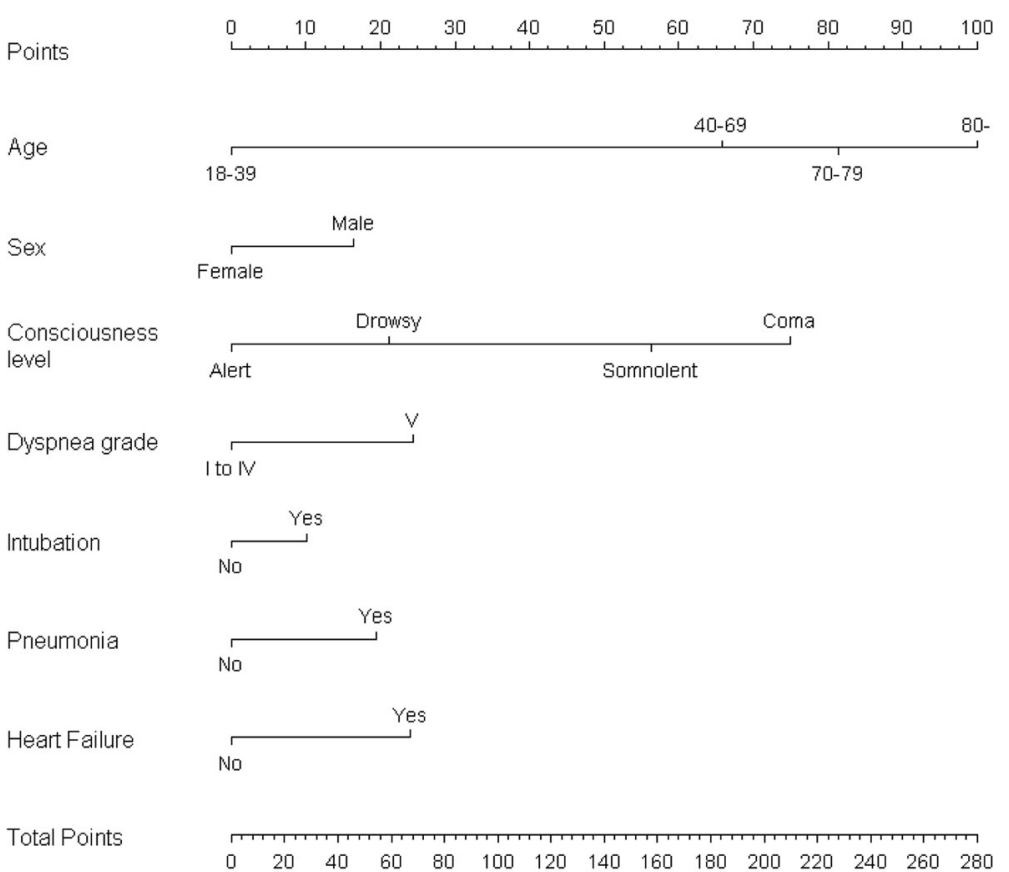

30 day Survival Probability

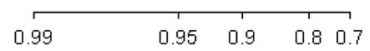

Fig. 2 A nomogram to predict in-hospital mortality in patients with asthma exacerbation. The patient's status for each predictor is plotted on the horizontal scale as axis points, and the vertical lines are drawn up to the axis points to obtain the corresponding points. After all points are summed, the total point score on the total point line is plotted and a vertical line is drawn down to the bottom line. The corresponding value shows the predicted probability of in-hospital death (for example, an 80-year-old (100 points) alert woman with pneumonia on admission (20 points) along with grade I dyspnea without any evidence of heart failure and requirement for tracheal intubation would score 120 points. Her 30-day survival probability is 0.95-0.99). Level of consciousness was estimated using the Japan Coma Scale, and dyspnea was estimated with Hugh-Jones classification. The term "intubation" refers to the intubation within 2 days of hospitalization 


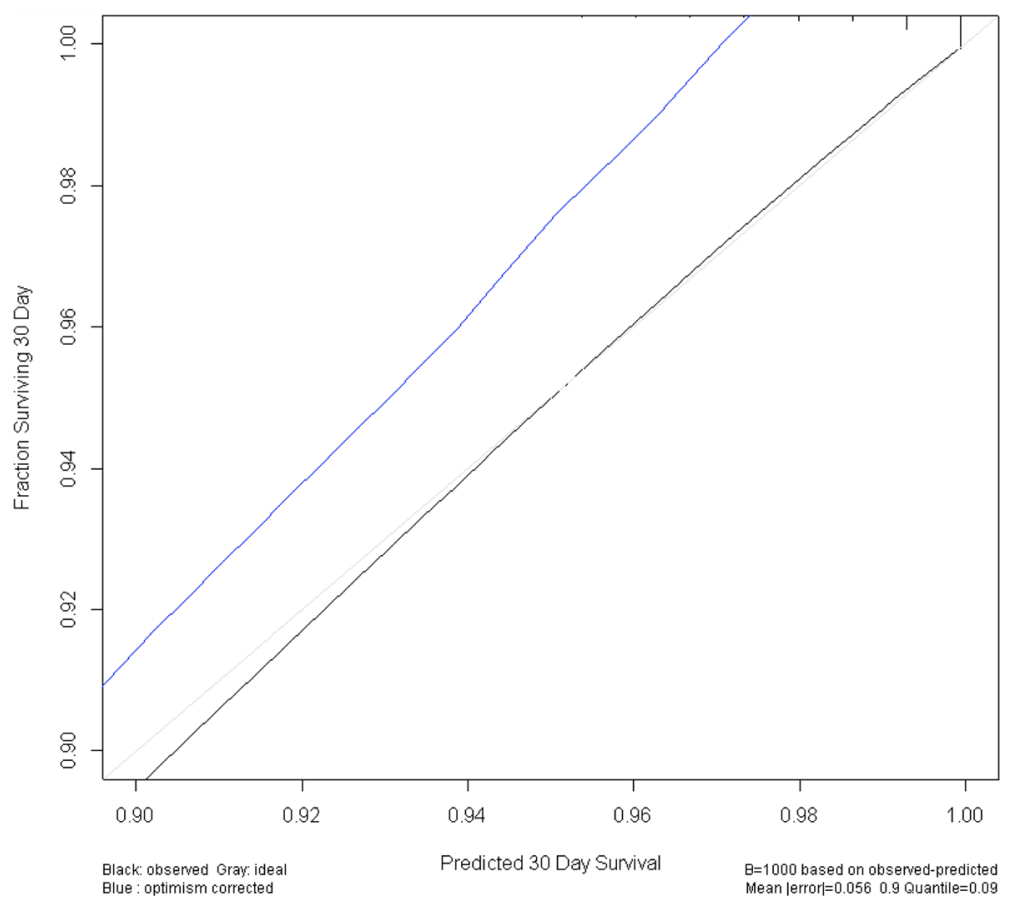

Fig. 3 Calibration plot. The gray line at $45^{\circ}$ indicates the ideal nomogram reference line. The black line shows the calculated data from the dataset. The optimism corrected line is an adjusted line generated by a bootstrap method with 1000 resamples

intubation/mechanical ventilation was $3.9 \%$, which is similar to that indicated by the previous US report (4.2\%) [5].

Patients with clinical features of both asthma and COPD have been referred to have "asthma COPD overlap" (ACO) syndrome [25]. Our previous study has demonstrated that compared with asthma alone, patients with ACO exhibit significantly higher in-hospital mortality [26]. In this study, although the in-hospital mortality of patients with ACO was higher than that of patients with asthma alone, the difference was not significant, probably because of the low death rate among the study population.

Previous studies have reported that short-term mortality of patients with asthma exacerbation is associated with older age $[5,23,24,27]$, male sex [5, 27], transferred on admission [5], mechanical ventilation [5, 27], past intubation [27-29], and more comorbid conditions $[5,27,29]$. Our study also identified these factors as the predictors of short-term in-hospital mortality in patients with asthma exacerbation. To the best of our knowledge, the present study reveals for the first time that in-hospital mortality is associated with lower level of consciousness.

Hypercapnia, which is defined as higher partial pressure of arterial $\mathrm{CO}_{2}$, is known to be associated with severe airway obstruction in patients with asthma and may impair the level of consciousness [30] and ability to talk or move. One previous study has reported no significant relationship between hypercapnia and death in outpatients with asthma [31], while another study has shown that higher partial pressure of arterial $\mathrm{CO}_{2}$ is associated with increased mortality in patients admitted to the intensive care unit with asthma exacerbation [32]. Thus, hypercapnia may be a potential risk factor associated with patient's mortality in extreme conditions. In this context, our study, which included such patients, may explain the association between impaired consciousness and asthma mortality in adults.

Our nomogram enables to predict a patient's risk of in-hospital death by evaluating simple parameters such as personal characteristics, medical history, and physical status at admission, without the need for complex examinations or investigations. One of the advantages of a nomogram is its ability to estimate individual risk in a simple and straightforward manner [17]. Nomograms are widely used as the prognostic devices in oncology $[16,17]$. In respiratory medicine, nomograms have been used to predict survival in patients with non-small cell lung cancer [33] or probability of asthma diagnosis [34]; however, we are the first to build a nomogram that predicts in-hospital mortality in patients with asthma exacerbation. Previous studies that have identified the risk factors associated with death in patients with asthma fail to identify the means of predicting the probability of death in individual patients. A nomogram can integrate the variables and relevant determinants of a disease into a 
prognosis [17]. With the present nomogram, physicians can easily estimate a patient's individual probability of death, which is helpful for clinical decision-making.

However, our study has certain limitations, one of which is the accuracy of asthma diagnosis. Because this study was a retrospective investigation based on information from an administrative database with de-identified data, we were unable to confirm how the patients were diagnosed with asthma. However, the diagnoses were recorded by the attending physicians, and we selected the patients who received systemic corticosteroid therapy for acute asthma attack soon after admission. Thus, we believe that the accuracy of the diagnosis in our study is adequate. Further, because the DPC database does not include detailed clinical information such as that regarding drugs used before or after admission, we could not evaluate the results of pulmonary function or blood tests, socioeconomic variables, symptoms before admission, and the baseline status of patients. Finally, because of missing data, we could not investigate the influence of smoking history on the outcome of asthma exacerbation.

\section{Conclusions}

All-cause in-hospital mortality in patients with asthma exacerbation is associated with older age, male sex, lower level of consciousness, pneumonia, and heart failure at admission. Our nomogram is a simple and straightforward means of helping physicians to predict individual risk of in-hospital death in patients with asthma exacerbation.

\section{Abbreviations}

ACO: And asthma COPD overlap; BMI: Body mass index; COPD: Chronic obstructive pulmonary disease; DPC: Diagnosis Procedure Combination; GERD: Gastroesophageal reflux disease; ICD-10: International Classification of Disease and Related Health Problems, 10th Revision; IQR: Interquartile range; SD: Standard deviation

\section{Acknowledgments}

Not applicable.

\section{Funding}

This work was supported in part by grants-in-aid for Scientific Research from the Ministry of Education, Science, Sports, Culture and Technology of Japan (YY, 15 K09211; TN, 16H02653), Grant to the Respiratory Failure Research Group, and Grants for Research on Policy Planning and Evaluation from the Ministry of Health, Labour, and Welfare, Japan (grant numbers: H28-Policy-Designated-009 and H27-Policy-Strategy-011). The funding body had no role.

\section{Availability of data and materials}

Data cannot be made publicly available for ethical reasons as the data are patient data.

\section{Authors' contributions}

WH: study design, data analysis, data interpretation, and manuscript preparation; YY: study design, data analysis, data interpretation, and manuscript preparation; HY: study design, data collection, data analysis, data interpretation, and manuscript preparation; $H T$ : study design and data interpretation; YS: study design and data interpretation; TJ: study design and data interpretation; YS: study design, data collection, data analysis, data interpretation, and manuscript preparation; HM: study design, data collection, data analysis, and data interpretation; KF: data collection and data interpretation; TN: study design, data interpretation, and supervision of the study. All authors approved the final manuscript.

\section{Ethics approval and consent to participate}

This study was approved by the Institutional Review Board of The University of Tokyo, which waived the requirement for patient informed consent because of the anonymous nature of the data.

Consent for publication

Not applicable.

\section{Competing interests}

The authors declare that they have no competing interests.

\section{Publisher's Note}

Springer Nature remains neutral with regard to jurisdictional claims in published maps and institutional affiliations.

\section{Author details}

'Department of Respiratory Medicine, Graduate School of Medicine, The University of Tokyo, 7-3-1 Hongo, Bunkyo-ku, Tokyo 113-8655, Japan. ${ }^{2}$ Department of Clinical Epidemiology and Health Economics, School of Public Health, Tokyo, Japan. ${ }^{3}$ Department of Health Services Research, Graduate School of Medicine, The University of Tokyo, Tokyo, Japan.

${ }^{4}$ Department of Health Policy and Informatics, Tokyo Medical and Dental University Graduate School of Medicine, Tokyo, Japan.

Received: 3 August 2016 Accepted: 26 July 2017

Published online: 04 August 2017

\section{References}

1. Global strategy for asthma management and prevention updated 2017 [Available from: http://ginasthma.org/2017-gina-report-global-strategy-forasthma-management-and-prevention/.

2. Suissa S, Ernst P, Benayoun S, Baltzan M, Cai B. Low-dose inhaled corticosteroids and the prevention of death from asthma. N Engl J Med. 2000;343(5):332-6.

3. Gupta D, Keogh B, Chung KF, Ayres JG, Harrison DA, Goldfrad C, et al. Characteristics and outcome for admissions to adult, general critical care units with acute severe asthma: a secondary analysis of the ICNARC case mix Programme database. Crit Care. 2004;8(2):R112-21.

4. Wenzel S. Severe asthma in adults. Am J Respir Crit Care Med. 2005; 172(2):149-60.

5. Krishnan V, Diette GB, Rand CS, Bilderback AL, Merriman B, Hansel NN, et al. Mortality in patients hospitalized for asthma exacerbations in the United States. Am J Respir Crit Care Med. 2006;174(6):633-8.

6. McFadden ER Jr. Acute severe asthma. Am J Respir Crit Care Med. 2003; 168(7):740-59.

7. Watson L, Turk F, James P, Holgate ST. Factors associated with mortality after an asthma admission: a national United Kingdom database analysis. Respir Med. 2007;101(8):1659-64.

8. Moorman JE, Rudd RA, Johnson CA, King M, Minor P, Bailey C, et al. National surveillance for asthma-United States, 1980-2004. MMWR Surveill Summ. 2007:56(8):1-54.

9. Vital statistics 2014 held by Ministry of Health, Labour and Welfare, Japan [Available from: http://www.mhlw.go.jp/toukei/saikin/hw/jinkou/kakutei14/ dl/11_h7.pdf.

10. Spitzer WO, Suissa S, Ernst P, Horwitz RI, Habbick B, Cockcroft D, et al. The use of beta-agonists and the risk of death and near death from asthma. $\mathrm{N}$ Engl J Med. 1992;326(8):501-6.

11. Suissa $S$, Blais $L$, Ernst $P$. Patterns of increasing beta-agonist use and the risk of fatal or near-fatal asthma. Eur Respir J. 1994;7(9):1602-9.

12. Suissa S, Ernst P, Boivin JF, Horwitz RI, Habbick B, Cockroft D, et al. A cohort analysis of excess mortality in asthma and the use of inhaled beta-agonists. Am J Respir Crit Care Med. 1994;149(3 Pt 1):604-10.

13. Lanes SF, Garcia Rodriguez LA, Huerta C. Respiratory medications and risk of asthma death. Thorax. 2002;57(8):683-6.

14. Jalaludin BB, Smith MA, Chey T, Orr NJ, Smith WT, Leeder SR. Risk factors for asthma deaths: a population-based, case-control study. Aust N Z J Public Health. 1999;23(6):595-600 
15. Ulrik CS, Backer V, Dirksen A. Mortality and decline in lung function in 213 adults with bronchial asthma: a ten-year follow up. J Asthma. 1992;29(1):29-38.

16. Iasonos A, Schrag D, Raj GV, Panageas KS. How to build and interpret a nomogram for cancer prognosis. J Clin Oncol. 2008;26(8):1364-70.

17. Balachandran VP, Gonen M, Smith JJ, DeMatteo RP. Nomograms in oncology: more than meets the eye. Lancet Oncol. 2015;16(4):e173-80.

18. Ohta T, Waga S, Handa W, Saito I, Takeuchi K. New grading of level of disordered consiousness (author's transl). No shinkei geka Neurological surgery. 1974;2(9):623-7.

19. Todo T, Usui M, Takakura K. Treatment of severe intraventricular hemorrhage by intraventricular infusion of urokinase. J Neurosurg. 1991; 74(1):81-6.

20. Fletcher $\mathrm{CM}$. The clinical diagnosis of pulmonary emphysema; an experimental study. Proc R Soc Med. 1952;45(9):577-84.

21. Hugh-Jones $P$, Lambert AV. A simple standard exercise test and its use for measuring exertion dyspnoea. Br Med J. 1952;1(4749):65-71.

22. Dunn RM, Lehman E, Chinchilli VM, Martin RJ, Boushey HA, Israel E, et al. Impact of age and sex on response to asthma therapy. Am J Respir Crit Care Med. 2015;192(5):551-8.

23. Tsai $C L$, Lee $W Y$, Hanania NA, Camargo CA Jr. Age-related differences in clinical outcomes for acute asthma in the United States, 2006-2008. J Allergy Clin Immunol. 2012;129(5):1252-8. e1

24. Goeman DP, Abramson MJ, McCarthy EA, Zubrinich CM, Douglass JA. Asthma mortality in Australia in the 21st century: a case series analysis. BMJ Open. 2013;3(5):e002539. doi:10.1136/bmjopen-2012-002539.

25. Global Initiative for Asthma and Global Initiative for Chronic Obstructive Lung Disease. Asthma, COPD, and asthma-COPD overlap syndrome. 2015 [Available from: http://ginasthma.org/asthma-copd-and-asthma-copdoverlap-syndrome-acos/.

26. Yamauchi $Y$, Yasunaga $H$, Matsui $H$, Hasegawa $W$, Jo T, Takami $K$, et al. Comparison of in-hospital mortality in patients with COPD, asthma and asthma-COPD overlap exacerbations. Respirology. 2015;20(6):940-6.

27. Pendergraft TB, Stanford RH, Beasley R, Stempel DA, Roberts C, McLaughlin T. Rates and characteristics of intensive care unit admissions and intubations among asthma-related hospitalizations. Ann Allergy Asthma Immunol. 2004;93(1):29-35.

28. Leatherman J. Mechanical ventilation for severe asthma. Chest. 2015:147(6): $1671-80$.

29. Kenyon N, Zeki AA, Albertson TE, Louie S. Definition of critical asthma syndromes. Clin Rev Allergy Immunol. 2015;48(1):1-6.

30. Sayers JA, Smith RE, Holland RL, Keatinge WR. Effects of carbon dioxide on mental performance. J Appl Physiol. 1987;63(1):25-30.

31. Mountain RD, Sahn SA. Clinical features and outcome in patients with acute asthma presenting with hypercapnia. Am Rev Respir Dis. 1988;138(3):535-9.

32. Afessa B, Morales I, Cury JD. Clinical course and outcome of patients admitted to an ICU for status asthmaticus. Chest. 2001;120(5):1616-21.

33. Liang W, Zhang L, Jiang G, Wang Q, Liu L, Liu D, et al. Development and validation of a nomogram for predicting survival in patients with resected non-small-cell lung cancer. J Clin Oncol. 2015;33(8):861-9.

34. Deng X, Gebretsadik T, Jin M, Gao YT, Bai C, Christman JW, et al. Development of a nomogram for identification of asthma among adults in epidemiologic studies. Ann Allergy Asthma Immunol. 2010;105(3):203-10.

\section{Submit your next manuscript to BioMed Central and we will help you at every step:}

- We accept pre-submission inquiries

- Our selector tool helps you to find the most relevant journal

- We provide round the clock customer support

- Convenient online submission

- Thorough peer review

- Inclusion in PubMed and all major indexing services

- Maximum visibility for your research

Submit your manuscript at www.biomedcentral.com/submit

) Biomed Central 